\title{
Tropospheric Ozone: a Menace for Crops and Natural Vegetation in Greece
}

\author{
Costas Saitanis* \\ Agricultural University of Athens, Laboratory of Ecology and Environmental Sciences \\ Iera Odos 75, Botanikos, 11855 Athens, Greece
}

Received 5 December 2007. Accepted 11 February 2008.

\begin{abstract}
Based on instrumental monitoring (AOT40s) and phytodetection (with Bel-W3 and KK6/5 tobacco cultivars) data we evaluated ambient ozone phytotoxicity in Greece.

In the greater region of Mesogia-Attica, during the summer of 2000, the year before the new airport Eleftherios Venizelos (March 2001) began operating in this region, the AOT40s (ppb*h) were 16,325 over 110 days at Spata; 18,646 over 113 days at Markopoulo; 8,093 over 22 days at Artemis and 16,679 over 121 days in Athens. The BelW3 and KK6/5 plants were extensively injured at all places with the greatest injury occurring at Artemis. During the same summer, ozone was also monitored in three rural areas of Corinth, at the Astronomical Observatory of Krionerion, Bogdani Hill and Kiato; The highest average daily AOT40 (192 ppb*h) was observed in Krionerio, and it was almost equal to that occurred in Athens $(193 \mathrm{ppb} * \mathrm{~h})$. Bel-W3 and KK6/5 plants placed at 11 rural areas in Corinth showed extended injury. The following year (2001), high injury was observed on other sets of bioindicator plants exposed in a network of 28 locations throughout the greater area of Volos and Pelion Mountain. Symptoms were more severe at Mortias, Xinovrisi, Tsagarada, Makrinitsa and Chania. The AOT40 (May-July) was 11,391 and $10,351 \mathrm{ppb} *$ hours for 2001 and 2002 respectively.

Severe ozone-like symptoms have also been observed on field-cultivated grape vines, onion and watermelon plants. Synoptically, our investigations suggest that ozone occurs in the Greek mainland at levels that are potentially phytotoxic for sensitive crop species and for sensitive natural vegetation species including forest trees.
\end{abstract}

Key-words: photochemical pollution, biomonitoring, bioindicators, pine forest, Bel-W3.

\section{Introduction}

Ozone $\left(\mathrm{O}_{3}\right)$ is an allotropic form of oxygen and is one of the most widespread and highly phytotoxic gases present in the troposphere. Its name originates from the Greek word "ozon" which as a noun means "peculiar smelling", while as a verb, "ozo", means "have a horrid and affective smell", (I stink), and thus defines an element of nature with the characteristic smell, which was already known in the Hellenic antiquity; according to Homer, this smell was attributed due to thunder and was characterized as divine (Iliad $\Xi^{\prime}$ '415), that is a smell of Zeus.

Nowadays it is well known that tropospheric ozone is a secondary air pollutant resulting from numerous photochemical reactions between the so called primary air pollutants, oxides of nitrogen and hydrocarbons, under sunlight conditions. It has been estimated that ozone levels in the northern hemisphere have doubled during the $20^{\text {th }}$ century and are increasing by an annual rate of $0.5-2.0 \%$ (Guicherit and Roemer, 2000).

Over recent decades, ozone has been recognized as the most widespread phytotoxic air pollutant affecting sensitive cultivated species and forest trees (Benton et al., 2000; Postiglione et al., 2000; Lorenzini and Saitanis, 2004; Ferretti et al., 2007a,b; Maggio et al., 2007). It has been now well established that ozone causes injury to sensitive plant species even at concentrations of some tenths of a part per billion by volume (ppbv). Furthermore, forest tree species, including pine trees, have been found to be affected by

\footnotetext{
* Corresponding Author: Tel.: +30 210 5294466; Fax: +30 210 5294462. E-mail address: saitanis@aua.gr
} 
ozone (Sanz et al., 1999; Sanz et al., 2000; Santamaría et al., 2003) and ozone is considered as one of the factors responsible for the so-called forest decline phenomenon.

Two approaches are usually used in the assessment of ozone phytotoxicity. The first concerns the instrumental monitoring of ozone concentrations and the assessment of the AOT40 index. The AOT40 (accumulated exposure over a threshold of $40 \mathrm{ppb}$ ) is calculated as the sum of the differences between the hourly concentration (ppb) and $40 \mathrm{ppb}$ for each hour when the concentration exceeds $40 \mathrm{ppb}$ and the global radiation exceeds $50 \mathrm{Wm}^{-2}$. The long-term critical level above which adverse effects on trees, crops and natural vegetation may occur has been defined as an AOT40 of 3,000 ppb*hours over three months for crops and 10,000 $\mathrm{ppb}^{*}$ hours over six months for forest trees (Fuhrer et al., 1997; Benton et al., 2000). The AOT40 index has become an European directive (Directive 2002/3/EC /12 Feb. 2002). The second approach is phytodetection (called also biomonitoring) which refers to the use of higher plants (usually Nicotiana tabacum var. BelW3 or Trifolium repens var. Regal) in detecting ozone occurrence at potentially phytotoxic levels, by scoring the extent of ozone-induced injury on their leaves (Lorenzini, 1994; Ribas et al., 1998; Peñuelas et al., 1999; Nali et al., 2001).

In southern European countries (Spain, Italy and Greece), ozone occurs at a higher level than in central or northern Europe (e.g. Fiala et al., 2003), due to higher sunlight radiation. Ozone induced visible injury has been observed throughout these countries to several crops and forest trees (Lorenzini and Saitanis, 2004).

In Italy, ambient potentially phytotoxic ozone levels have been reported to occur since the early nineties (Postiglione and Fagnano, 1993; Postiglione and Fagnano, 1995). Yield losses due to ozone in Italy have been reported for peach (Paolacci et al., 1995), lettuce (Postiglione and Fagnano, 1995), durum wheat (Pleijel et al., 2004), tomato (Postiglione and Fagnano, 1995), beans (Postiglione et al., 1996; Postiglione and Fagnano, 1995) and subterranean clover (Postiglione and Fagnano, 1995). Other investigations have demonstrated the potential ozone phytotoxicity using bioindicator plants (Toncelli and Lorenzini, 1999; Nali et al., 2001). Postiglione et al. (2000), reported results showing that ozone levels in Naples caused visible injury to the plants of the ozone sensitive white clover clone (NC-S), but not to resistant ones (NC-R), and significantly reduced leaf and stolon dry matter production of NC-S in comparison to NC-R. Ferretti et al., 2007b, have reviewed the literature concerning researches conducted over recent years about levels, uptake and vegetation response to $\mathrm{O}_{3}$ in Italy.

In Spain, several research teams have conducted monitoring and biomonitoring investigations to evaluate ozone phytotoxicity, and they have reported ozone induced injury in fieldgrowing oat (Carrasco-Rodriguez and Valle-Tascon, 2001), severe symptoms in cabbage growing in open top chambers (Calatayud et al., 2002) and yield reduction in watermelon cultivations (Gimeno et al., 1999; Fernandez-Bayon et al., 1993; Reinert et al., 1992). Beech (Santamaría et al., 2003) and Aleppo pine (Sanz et al., 1999; Sanz et al., 2000) forests have also been reported to be affected by ambient ozone. Biomonitoring explorations with Bel-W3 have additionally confirmed the occurrence of ambient ozone at potentially phytotoxic levels (Ribas and Peñuelas, 2003) in Spain.

Although in Italy and Spain ozone phytotoxicity has been studied by several research teams for many years, the relevant investigations in Greece are extremely limited. However, the climatic conditions in these three Mediterranean countries are more or less similar; they have similar latitude and similar sunlight intensity, and are strongly climatically affected by the Mediterranean sea; the flora is also similar. It is thus expected that ozone levels in Greece to be also increased. Over the last years we have explored ozone phytotoxicity in urban, suburban and rural areas of Greece in an effort to reveal the occurrence of ozone at potentially phytotoxic levels in Greece (Saitanis et al., 2000; Saitanis et al., 2001; Saitanis and Karandinos, 2001, 2002; Saitanis, 2003; Saitanis et al., 2003; Saitanis et al., 2004). Since the beginning of '90, we conducted a pilot exploration by exposing Bel-W3 plants at several stations some of them scattered within the greater region of Athens (Karandinos and Saitanis, 1992a, 1992b) and others located in rural areas throughout the country (Saitanis and Karandinos, 2001). We observed high injury in the most of the stations which suggested us to conduct 
better established investigations. In our investigations we applied both instrumental monitoring and phytodetection approaches. I synoptically present here some of the results obtained till now, showing that ambient ozone levels in Greece are high enough to be potentially phytotoxic at least for the sensitive species; additional research monitoring continues. The study areas discussed here are Athens (urban), the greater area of Mesogia-Attica (suburban), the greater rural area of Corinth (agricultural), and the greater area of Volos town and the nearby Pelion Mountain (forest) (Fig. 1).

\section{Material and methods}

Ozone monitoring data were either collected by our UV Photometric ozone analyzer (Model 1108, Dasibi corp.) or provided by the Directorate of Air and Noise Pollution Control of the Ministry of Environment or by the Department of Environment and Quality of Athens' International Airport El. Venizelos.

From the data of hourly ozone concentrations we calculated the AOT40 index for the places under monitoring. Besides, other data, like meteorological conditions, were gathered and considered in the explanations of the results obtained from each experiment.

In Attica, monitoring data (along with phytodetection data) concern one urban station in the Campus of Agricultural University in the metropolitan area of Athens and three suburban stations in the nearby Mesogia plain (Spata, Markopoulo, Artemis) and covered the summer months of the year 2000, the year before the new airport Eleftherios Venizelos began operating in this region (March 2001) (Saitanis et al., 2003).

During the same summer, ozone concentrations were additionally monitored in three places in three rural areas of Corinth prefecture (namely Bogdani hill, Astronomical Observatory of Krionerion and Kiato) and compared with ambient ozone monitored in Athens. In addition, phytodetection exploration was conducted in 12 stations in villages scattered in the greater rural region of Corinth (Saitanis et al., 2000; Saitanis 2003).

The hourly ozone concentrations monitoring data in the rural town of Volos, located at the

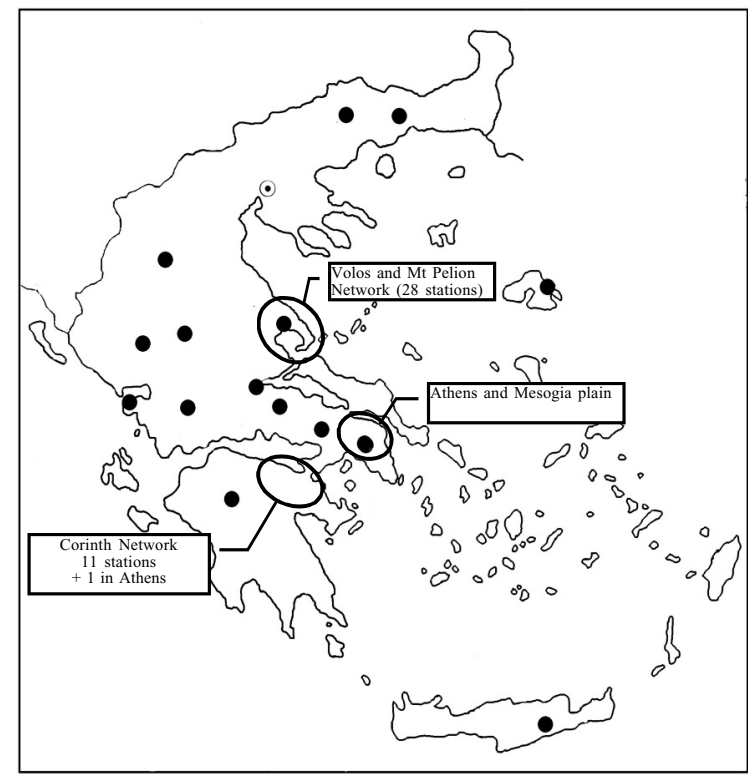

Figure 1. A map of Greece showing the monitoring and phytodetection Networks discussed in this paper. The black spots show other stations at which pilot phytodetection was conducted since early 90's (Saitanis and Karandinos, 2001).

foot of Pelion Mt., over the years 2001 and 2002, were analysed. In the greater region a network of 28 phytodetection stations was established covering the city of Volos, some villages in the surrounding agricultural areas while the majority of the stations were scattered throughout the Forest of Pelion mountain (which is characterized a "forest of natural beauty") (Saitanis et al., 2004).

For the phytodetection survey, plants of Bel-W3 and KK6/5 tobacco cultivars, which are known to have a sensitive thresold of about 4050 and $60-80 \mathrm{ppb}$ respectively, were used. Ozone usually causes characteristic visible injury consisting of chlorotic and necrotic spots which in the cases of weak injury are usually restricted on the upper surface of the leaves while in the cases of severe injury are bifacial.

Seedlings of the bioindicator plants were grown under laboratory conditions. The seedlings were planted in pots and grown in a walk-in controlled-environment chamber (230x 190x170 cm Model 60R - CDR corp.) under the same conditions: 14:10 (L:D) h photoperiod, $63 \pm 3 \%$ relative humidity and $28 \pm 0.5{ }^{\circ} \mathrm{C}$ temperature, where the ambient air was purified by passing through activated charcoal-purafill fil- 
ters. When plants reached the stage of 6-8 leaves, they were transferred (potted) to the monitoring locations. Five to six plants per monitoring station were used.

After a week of exposure we evaluated the extent of macroscopic symptoms on each leaf of each plant used. The extent of the injury was estimated as the percentage of leaf area showing the characteristic ozone induced symptoms. Then we calculated the mean of the percentages of injury from all the leaves of each plant. The mean of the leaf injured areas percentages, of all the plants of each site constituted the visible injury index (VII) of that site.

For further checking of the causal factor of the macroscopic symptoms, some of the field exposed plants were brought back into the laboratory chambers for further growth and observations on the newly expanded leaves. Moreover, we tested the exposed plants for possible virus infection.

\section{Results}

The ozone concentrations in Athens and in the three stations in Mesogia plain showed the usual diurnal profile: they reached their maximum values during midday and afternoon hours and their minimum values during night hours. The average hourly ozone concentration during the early afternoon hours, when ozone reaches its maximum, ranged from 50-70 ppb while the 24hours average ranged from 25 to $65 \mathrm{ppb}$. The AOT40 (ppb*hours) index was very high in Athens (16679 over 121 days), Spata (16325 over 110 days), Artemis (8093 over 22 days) and Markopoulo (18646 over 113 days), indicating that the ozone levels should be considered potentially phytotoxic, since these values were much higher than the $3000 \mathrm{ppb}^{*} \mathrm{~h}$ (over 90 days)
UN/ECE threshold (Bull et al., 1996). The average daily AOT40 - for comparison purpose were $138,148,368$ and 165 ppb*hours respectively. The ozone bioindicator plants of Bel-W3 and KK6/5 tobacco varieties were highly injured at all regions, thus confirming the phytotoxic potential of those ozone levels. The most injured plants were those exposed at Artemis where ozone concentrations were found to be the highest (Saitanis et al., 2003).

In the greater agricultural region of Corinth, the average daily AOT40 (ppb*hours) was 212 at Bogdani hill, 192 at the Astronomical Observatory and 47 in Kiato (Tab. 1). The ozone concentrations in Kiato were relatively low because the monitoring was made during September when ozone levels are lower than during the summer months. The ozone injury in Bel-W3 plants was higher at the higher altitude places of the Astronomical Observatory and Mogostos and lower in the small coastal city of Kiato (Saitanis et al., 2000; Saitanis 2003).

In the town of Volos, the AOT40 calculated over the periods of three moths (May to July) and of six months (April to September) were 11,391 and 19,234 ppb*hours for the year 2001 and 10,351 and $14,276 \mathrm{ppb}^{*}$ hours for the year 2002, respectively. These values of AOT40s were higher than the thresholds suggested by European directive (Directive 2002/3/EC /12 Feb. 2002) as causing visible injury to vegetation and to forest trees. The short-term AOT40 showed that ozone occurred at phytotoxic levels from early spring to late autumn period.

Severe symptoms were observed on the BelW3 plants at a sufficient number of sites. Symptoms were more severe at the eastern sites of Pelion (Mortias, Xinovrisi, Tsagarada, etc.) and at the sites of higher altitude (Makrinitsa, Chania) (Saitanis et al., 2004).

In addition to typical and easily recognizable

Table 1. The AOT40 values monitored in three rural places in Corinth prefecture in comparison with the values in Athens. At Kiato $(*)$ the monitoring was conducted during September and this may explain the low ozone levels monitored (Saitanis, 2003).

\begin{tabular}{lcccc}
\hline & Period & Monitoring & \multicolumn{2}{c}{ AOT40 $\left(\mathrm{ppb}{ }^{* h}\right)$} \\
\cline { 2 - 5 } Region (Altitude, m) & $(2000)$ & Days & SUM & Daily average \\
\hline Athens (50) & $18 / 6-31 / 7$ & 44 & 8497 & 193 \\
Bogdani hill (300) & $18 / 6-1 / 8$ & 45 & 9532 & 212 \\
Observatory (920) & $6 / 8-28 / 8$ & 23 & 4406 & 192 \\
Kiato (5) & $29 / 8-21 / 9 *$ & 24 & 1126 & 47
\end{tabular}


ozone-induced symptoms on Bel-W3 plants, ozone-like symptoms were observed on fieldgrown plants of cultivated species, (mainly grapevines, tobacco, watermelon and onion) and forest trees (pines), in several regions of the country. Plants of some of these species are now being exposed to ozone under laboratory conditions for further investigation of their response to ozone.

\section{Discussion}

The gathered monitoring data show ozone concentrations well above the threshold of $40 \mathrm{pp}$ bv and the calculated AOT40 values were many times above the threshold of $3000 \mathrm{ppbv}^{*} \mathrm{~h}$, suggesting that field growing plants in Greece are at high risk to be injured from ambient ozone. The AOT40 index, however, should be considered an indication and not a proof of ozone injury. Although this index is easy to use, it obliviously has some weaknesses. The index has been established for the entire Europe and ignores the climatic differences between northern and southern European countries. It does not also considered the microclimatic conditions where the plants grow and does not takes into account the differences of species between northern and southern European flora. It is obvious that different indices should be developed for northern and southern European countries, which should also be specific for each species or at least for groups of species.

Other approaches, based on fluxes have been proposed to replace the AOT40 index. However, "while the flux-based approach is scientifically sounder, a more practical concentrationbased approach is still necessary for routine monitoring" (Ferretti et al., 2007a). Thus, at the time, according to the available scientific knowledge and experience, the AOT40 is not a good index but is the best available.

The ozone-bioindicator plants exposed in the above mentioned investigated areas, showed the well known characteristic and easily recognizable symptoms. We have also seen ozone-like symptoms on field-grown plants of cultivated species (including grapevines, tobacco, watermelon and onion) and forest trees (Alepo pines), in other regions of Greece. However, the field evidence of $\mathrm{O}_{3}$ effects on crops and especially on forests is still considered extremely limited. Evidence like discoloration, defoliation, chlorosis, necrotic spots, stippling, etc, widely observed in field growing plants, are non-specific response indicators since they may be caused by many other environmental and/or biological factors (Innes, 1993; Ferretti et al., 2007a). Besides, the timing of the exploration for symptoms plays an important role because the phenology of the symptoms is more closely related to the phenology of the vegetative apparatus especially of the herbaceous species (Bussotti et al., 2006). Meteorological conditions also determine the response of plants to ozone by affecting stomatal conductance (Gerosa et al., 2003).

Of course the results obtained by bioindicator plants are attributed to ozone with high confidence. However, such bioindicator plants, like Bel-W3, white clover (NC-S and NS-R clones) and brown knapweed (Centaurea jacea L.), originated from USA and northern European countries and are not well adapted to the Mediterranean environment. Thus, extrapolation of the results obtained by bioindicator plants to field grown plants in Mediterranean countries should be made by caution. The native vegetation (including forest) species have obviously developed some mechanisms of adaptation to the Mediterranean climatic condition. Although such mechanisms may, as a side effect, allows plants to overcome ozone stress easier than the bioindicator plants, in this environment, such mechanism should not be considered as adaptation to increased ozone concentrations; gradually increasing of ozone concentrations occurs only over the last few decades while adaptation mechanisms needs much more time to be developed and observed at this scale.

Nevertheless, although the identification of symptoms under field conditions is very difficult and risky, the data suggest that field growing plants, at least the sensitive species, may suffer from the nowadays occurring ambient ozone levels and even without symptoms, the plants may be depressed by ozone and some yield loss should be expected.

Synoptically, both the approaches, instrumental recording and phytodetection, suggest that background ozone levels occurring in the Greek mainland should be considered potentially phytotoxic at least for sensitive plant 
species. Taking into account that the ozone levels have doubled during the $20^{\text {th }}$ century and are gradually increasing, our results suggest that some of the plant species that are not affected by ambient ozone levels today, may be at risk in the near future. The diurnal pattern of ozone concentrations should be further investigated in conjunction with the diurnal pattern of stomatal conductance, for a better understanding of ozone phytotoxicity. More extended investigations are needed to evaluate the impact of ozone on cultivated species and on the forest ecosystems in Greece.

\section{Acknowledgements}

This investigation was partly financed by General Secretary of Research and Technology of Greece - Joint Research and Technology Programmes - in the frameworks of the Greece-Ukraine and the Greece-Egypt bilateral projects.

\section{References}

Benton J., Fuhrer J., Gimeno B.S., Skärby L., PalmerBrown D., Ball G., Roadknight C., Mills G. 2000. An international cooperative programme indicates the widespread occurrence of ozone injury on crops. Agriculture Ecosystem Environment, 78:19-30.

Bull K.1996. Workshop Summary. In: Karenlampi L., Skarby L. (eds.): Critical levels for ozone in Europe, Testing and finalizing the concepts, 7-8. UN-ECE Workshop Report, University of Kuopio, Department of Ecology and Environmental Science, Finland.

Bussotti F., Schaub M., Cozzi A., Gerosa G., Novak K., Hug C. 2006. Sources of errors in assessing ozone visible symptoms on native vegetation. Environmental Pollution, 140:257-268.

Calatayud A., Alvarado J.W., Barreno E. 2002. Differences in ozone sensitivity in three varieties of cabbage (Brassica oleracea L.) in the rural Mediterranean area. J. Plant Physiology, 159:863-868.

Carrasco-Rodriguez J.L., Valle-Tascon S. 2001. Impact of elevated ozone on chlorophyll a fluorescence in fieldgrown oat (Avena sativa). Environmental Experimental Botany, 45:133-142.

Fernandez-Bayon J.M., Barnes J.D., Ollerenshaw J.H., Davison A.W. 1993. Physiological effects of ozone on cultivars of watermelon (Citrullus lanatus) and muskmelon (Cucumis melo) widely grown in Spain. Environmental Pollution, 81:199-206.

Ferretti M., Bussotti F., Calatayud V., Schaub M., Kräuchi N., Petriccione B., Sanchez-Peña G., Sanz M.J., Ulrich E. 2007a. Ozone and forests in South-Western Europe. Environmental Pollution, 145:617-619.
Ferretti M., Fagnano M., Amoriello T., Badiani M., Ballarin-Denti A., Buffoni A., Bussotti F., Castagna A., Cieslik S., Costantini A., De Marco A., Gerosa G., Lorenzini G., Manes F., Merola G., Nali C., Paoletti E., Petriccione B., Racalbuto S., Rana G., Ranieri A., Tagliaferri A., Vialetto G., Vitale M. 2007b. Measuring, modelling and testing ozone exposure, flux and effects on vegetation in southern European conditions - What does not work? A review from Italy. Environmental Pollution, 146:648-658.

Fiala J., Cernikowsly L., de Leeuw F., Kurfuerst P. 2003. Air pollution by ozone in Europe in summer 2003. European Environment Agency. Topic Report 3/2003, $33 \mathrm{pp}$.

Fuhrer J., Skarby L., Ashmore M.R. 1997. Critical levels for ozone effects on vegetation in Europe. Environmental Pollution, 97:91-106.

Gerosa G., Cieslik S., Ballarin-Denti A. 2003. Micrometeorological determination of time-integrated stomatal ozone fluxes over wheat: a case study in Northern Italy. Atmospheric Environment, 37:777-788.

Gimeno B.S., Bermejo V., Reinert R.A., Zheng Y., Barnes J.D. 1999. Adverse effects of ambient ozone on watermelon yield and physiology at a rural site in Eastern Spain. New Phytologist, 144:245-260.

Guicherit R., Roemer M. 2000. Tropospheric ozone trends. Chemosphere - Global Change Science, 2: 167-183.

Karandinos M.G., Saitanis C. 1992a. Response of BelW3 tobacco plants to ozone in several sites of the Greater Athens Region of Greece. In: J. Bohac (ed.): Bioindicators Deteriorisationis Regionis. Proc. of the $6^{\text {th }}$ International Conference, 15-21 September 1991, Ceske Budejovice (CZ), 194-201.

Karandinos M.G., Saitanis C. 1992b. Ozone effects on Bel-W3 and Greek tobacco varieties in the greater Athens region. Proc. CORESTA International Congress, 11-16 October 1992, Jerez de la Frontera (E), 234-244.

Innes J.L. 1993. Forest Health: its Assessment and Status. CAB International, Wallingford, Oxon (UK). 677 pp.

Lorenzini G. 1994. A miniaturized kit for ozone biomonitoring. Applied Biochemistry Biotechnology, 34:59-62.

Lorenzini G., Saitanis C.J. 2004. Ozone: A novel plant "pathogen". In: Sanità di Toppi L., Pawlik-Skowrońska B. (eds.): Abiotic Stresses in Plants. Kluwer Academic Publishers. 256 pp.

Maggio A., De Pascale S., Fagnano M., Barbieri G. 2007. Can salt stress-induced physiological responses protect tomato crops from ozone damages in Mediterranean environments? European Journal of Agronomy, 26:454-461.

Nali C., Ferretti M., Pellegrini M., Lorenzini G. 2001. Monitoring and biomonitoring of surface ozone in Florence, Italy. Environment Monitoring Assessment, 69:159-174. 
Paolacci A.R., Badiani M., D’Annibale A., Bignami C., Fumagalli I., Fusari A., Lorenzini G., Matteucci G., Mignanego L., Rossigni F., Schenone G., Giovannozzi Sermanni G. 1995. The effects of realistic ozone exposure on the biology and productivity of peach trees and durum wheat grown in open-top chambers in Central Italy. Agricoltura Mediterranea, S.V.:125-139.

Peñuelas J., Ribas A., Gimeno B.S., Filella I. 1999. Dependence of ozone biomonitoring on meteorological conditions of different sites in Catalonia (N.E. Spain). Environment Monitoring Assessment, 56:221224.

Pleijel H., Danielsson H., Ojanperä K., De Temmerman L., Högy P., Badiani M., Karlsson P.E. 2004. Relationships between ozone exposure and yield loss in European wheat and potato - a comparison of concentration and flux based exposure indices. Atmospheric Environment, 38:2259-2269.

Postiglione L., Fagnano M. 1993. Danni da ozono ed azione protettiva dell'etilendiurea. Primi risultati sperimentali su fagiolo. Agricoltura Ricerca, 149:57-62.

Postiglione L., Fagnano M. 1995. Ozone injury and ethylene diurea: first results on different species in Campania region. Agricoltura Mediterranea S.V.:109-118.

Postiglione L., Fagnano M., Merola G. 1996. Danni da ozono ed azione protettiva dell'EDU su differenti cultivar di fagiolo (Phaseolus vulgaris L.). Risultati di un biennio. Proceedings of the VII SItE Congress 17, 11-14 September 1996, Naples, 753-756.

Postiglione L., Fagnano M., Merola G. 2000. Response to ambient ozone of two white clover (Trifolium repens L.cv. "Regal") clones, one resistant and one sensitive, grown in a Mediterranean environment. Environmental Pollution, 109:525-531.

Reinert R., Sanchez B., Salleras J-M, V Bermejo, Ochoa M. J., Tarruel A. 1992. Ozone effects on watermelon plants at the Ebro Delta (Spain): symptomatology. Agriculture Ecosystem Environment, 38:41-49.

Ribas A., Filella I., Gimeno B.S., Peñuelas J. 1998. Evaluation of tobacco cultivars as bioindicators and biomonitors of ozone phytotoxical levels in Catalonia. Water Air Soil Pollution, 107:347-365.

Ribas A., Peñuelas J. 2003. Biomonitoring of tropospheric ozone phytotoxicity in rural Catalonia. Atmospheric Environment, 37:63-71.

Saitanis C.J. 2003. Background ozone monitoring and phytodetection in the greater rural area of Corinth - Greece. Chemosphere, 51:913-923.

Saitanis C.J., Karandinos M. 2002. Effects of ozone on tobacco (Nicotiana tabacum L.) varieties. Journal of Agronomy and Crop Science, 188:51-58.

Saitanis C.J., Karandinos M.G. 2001. Instrumental recording and biomonitoring of ambient ozone in Greek countryside. Chemosphere, 44:813-821.

Saitanis C.J., Riga-Karandinos A.N., Karandinos M.G. 2001. Effects of ozone on chlorophyll and quantum yield of tobacco (Nicotiana tabacum L.) varieties. Chemosphere, 42:945-953.

Saitanis C.J., Karandinos M.G., Lekkas D. 2000. Tropospheric ozone monitoring in a Pine forest close to Korinthos - Greece. Pan-Hellenic Phytopathological Congress, 3-5 October 2000, Kalamata (G). 66 pp.

Saitanis C.J., Karandinos M.G., Riga-Karandinos A.N., Lorenzini G., Vlassi A. 2003. Photochemical air pollutant levels and ozone phytotoxicity in the region of Mesogia-Attica, Greece. Int. J. Environmental Pollution, 19:197-208.

Saitanis C.J., Katsaras D.H., Riga-Karandinos A.N., Lekkas D., Arapis G. 2004. Evaluation of ozone phytotoxicity in the greater area of a typical mediterranean small city (Volos) and in the nearby forest (Pelion Mt.) - Central Greece. Bulletin of Environmental Contamination and Toxicology, 72:1268-77.

Santamaría J.M., Amores G., Garrigó J., Gimeno B.S., Luchetta L., Madotz N., Cavero R., Ederra A. 2003. An intensive monitoring study of air pollution stress in a beech forest in Spain. In: Karnosky D. (ed.): Air pollution, global change and forests in the new millennium, 359-374. Developments in environmental science, 3. Elsevier Sci., Amsterdam.

Sanz M.J. Calatayud V., Calvo E. 1999. Spatial pattern of ozone injury in aleppo pine and air pollution dynamics in the Mediterranean. Physics and Chemistry of the Earth, Part C: Solar, Terrestrial \& Planetary Science, 24:495-498.

Sanz M.J., Calatayud V., Calvo E. 2000. Spatial pattern of ozone injury in Aleppo pine related to air pollution dynamics in a coastal-mountain region of eastern Spain. Environmental Pollution, 108: 239-247.

Toncelli M., Lorenzini G. 1999. Comparative evaluation of biomonitoring techniques of tropospheric ozone. Environment Monitoring and Assessment, 55:445-458. 